\title{
Scripta
}

\section{Juegos de palabras y música en El Cortesano de Luis Milán}

\author{
Play on words and music in El Cortesano of Luis Milán
}

\author{
Alfonso Colella \\ alfonso.colella@istruzione.it \\ Universidad de Santander
}

\begin{abstract}
Resumen: Este artículo analiza cómo, en El Cortesano, la música y la actuación musical se ven fuertemente afectadas por el carácter burlesco e ingenioso de todos los personajes que frecuentan las reuniones de Fernando de Aragón y de la reina Germana de Foix. Por lo tanto, el músico Milán, para cumplir con todas las expectativas de este mundo del entretenimiento y del juego, debe basarse necesariamente en una serie de opciones interpretativas que permitan actuaciones rápidas en función de las demandas de su público. Lo que emerge es una imagen del músico y de la música diferente de lo que se esperaría normalmente. En una sociedad de este tipo, no cuenta la música entendida en su estética y aspectos técnicos, sino la capacidad de gestionar las apariencias y someterse a las pruebas y los mandatos impuestos por los rituales del juego cortesano. Tenemos muchos ejemplos en que Milán se muestra con pasividad y sumisión. Pero es normal, porque esto entra en los códigos de la vida de la corte.
\end{abstract}

Paraules clau: Fernando de Aragón, duque de Calabria, El Cortesano, Libro de motes, Las siete angustias de amor, improvisación, juegos de palabras

\begin{abstract}
This article takes into consideration El Cortesano (1561) by Luis Milán: in this text the musical performance is strongly influenced by the playful attitudes of the individuals who attended the court meetings of Fernando de Aragón and Germana de Foix. Therefore, the musician has to keep in mind every expectation of courtly entertainment and gaming, and morevoer he must open his interpretative options to meet also the demands of the public. What emerges is a picture of the musician and his music that is different from what one would expect in another social context. In such aristocratic society as the Duke of Calabria, music was not understood only in terms of its aesthetic values and technical aspects, but it also required that the player accepted the rituals of the courtly game.
\end{abstract}

Keywords: Fernando de Aragón, duke of Calabria, El Cortesano, Libro de motes, Las siete angustias de amor, improvisation, gemes of words

DATA PRESENTACIÓ: 18/04/2015 ACCEPTACIÓ: 12/05/2015 ·PUBLICACIÓ: 12/06/2015

SCRIPTA, Revista internacional de literatura i cultura medieval i moderna, núm. 5 / juny 2015 / pp. 229 - 252 


\section{Preliminar}

El Libro titulado el Cortesano de Luis Milán, que se publicó en Valencia en el 1561, bien representa la vida literaria, las prácticas musicales y el otium de la corte virreinal con todos sus juegos y hobbies. ${ }^{1}$ Como ya ha sido señalado por Escartí, esta obra no solo pude ser considerada como una especie de crónica, a menudo idealizada, de las reuniones palaciegas del duque de Calabria don Fernando de Aragón y Germana de Foix, sino más bien como la parte final de un proyecto educativo para la nobleza valenciana que se inició con la publicación del Libro de motes de damas y caballeros (1535) y siguió con ElMaestro (1536) (Milà 2001: 54-55). ${ }^{2}$ En el Libro de motes, el entretenimiento y la evasión venían servidos en forma de motes (juegos de palabras con un propósito específico), en El Maestro, en forma de música en cifras -también para facilitar la lectura a los aficionados y no expertos- y, finalmente, en El Cortesano, en forma mixta de diálogos lúdicos y música.

La obra se estructura en seis jornadas y relata varios entretenimientos de cortesanos valencianos, pasando por la recitación de poesías, actuaciones musicales, juegos de motes y pullas, representaciones de farsas, máscaras y torneos. Dentro de toda la narración destacan episodios clave como La caz̧a (I jornada), La Farsa de las galeras de Sanct Joan (III jornada), La Montería de las damas y caballeros de Troya (IV jornada), Las Fiestas de Mayo y Máscara de los Troyanos (VI jornada).

Me centraré en la VI jornada de esta obra porque, además de caracterizarse por su unidad dialógicodramática, brinda también mucho material para investigar y entender lo que es el papel y la función de la música en la corte virreinal de Valencia, en su apogeo político y cultural. ${ }^{3}$

1 Escrito alrededor de 1535, pero probablemente revisado más tarde, el libro fue publicado en 1561 en Valencia. Las ediciones modernas son: Luis Milán, Libro intitulado El Cortesano, compuesto por D. Luis Milán [...], Madrid, Aribau y Cia., 1874; Lluís del Milà, El cortesano, Vicent Josep Escartí (ed.) i Vicent J. Escartí \& Antoni Todera (introd.), València, Biblioteca Valenciana-Ajuntament de València-Universitat de València, 2001, 2 vols; Lluís del Milà, El cortesano, ed. y estudo introductorio por Vicent Josep Escartí, Valencia, Institució Alfons el Magnànim, 2010. En cuanto a las citas, me voy a referir a esta última edición porque regulariza la ortografía según el castellano y el catalán moderno. A partir de ahora las citas aparecerán en números arábigos, entre corchetes.

2 Sobre el componente ficticio de la obra, véase Cruilles (2007: 406) y Solervicens i Bo (1997: 174-180). En cuanto al Libro de motes, me referiré siempre a la edición crítica de Vega Vázquez (2006).

3 En la VI jornada confluyen casi todos los generos poético-musicales presentes en los Cancioneros de aquel entonces (romances, letras, motes y sus glosas, villancicos, tercetos y, sobre todo, sonetos). Además, en El Cortesano encontramos huellas de diversos textos poéticos que forman parte del Cancionero de Uppsala (Venecia, 1556), del Cancionero de Romances (Amberes, 1548) y del Cancionero General (Valencia, 1511). Se trata de tres obras con un trasfondo cultural valenciano. 


\section{Tan poca pena diesen en sentirlas como en oírlas (I)}

Como en el transcurso de toda la obra, también durante esta VI jornada los interlocutores preferenciales de Milán son el duque de Calabria, Fernando de Aragón, y la reina Germana de Foix con su séquito de damas. Sin embargo, también son importantes las figuras de Juan Fernández de Heredia, Francisco Fenollet y Diego Ladrón que, además de ser poetas y literatos destacados, parecen dar prueba de una cierta competencia en ámbito musical. ${ }^{4} \mathrm{Al}$ inicio, toda la corte se desplaza al Palacio Real en espera de que se celebren las Fiestas de Mayo y la Máscara de los Troyanos. Pero a nosotros nos interesa lo que sucede antes de eso, en toda una serie de secuencias de eventos musicales intercalados en diálogos concisos.

Al principio, Milán entona Las Siete angustias de amor [300-303]. El título de esta poesía de amor cortés parafrasea las siete angustias de la Virgen, argumento muy tratado por la mística de aquella época. Se trata de uno de sus textos poéticos ya compuestos, muy populares entre sus amigos y cortesanos, y que luego confluyeron en El cortesano. El texto se compone de nueve estrofas de nueve versos cada una. En cada estrofa Milán enfoca un tema típico del amor cortés que encuentra sus raíces ya en el tratado de Andrea Cappellano, De Amore, redactado en 1185 aproximadamente. Los componentes desagradables del amor no correspondido que aparecen en el texto son: la tristeza, la lejanía, el pudor de la mujer, la desilusión, la súplica y el rechazo de ella hacia él, el olvido, el desdén que prueba el amante cuando se siente rechazado, los celos. El esquema de las rimas es irregular, y en todas las coplas cantadas por Milán, vuelve la imagen más clásica de las relaciones imposibles entre la dama inalterable y el cortejador desesperado por conseguir el más mínimo signo de interés, o, por lo menos, de falta de hostilidad. Milán entona su texto tocando la vihuela, que, en este episodio, como en otros muchos, juega un papel fundamental en el desarrollo de la diversión y del festejo cortesano. ${ }^{5}$

4 Los nombres de estos miembros de la corte virreinal están presentes en el Cancionero General de Hernando del Castillo (Valencia, 1511), por lo que se trata de poetas y literatos bien conocidos. Durante la VI jornada, Francisco Fenollet canta una canción y una glosa acompañándose con un instrumento y Diego Ladrón, en un cierto punto, pide una vihuela para discantar sobre un soneto de Milán. En general, los nobles que están presentes en la corte, están acostumbrados a oír e incluso interpretar música cantada (Dumanoir 1998: 111).

\section{Las siete angustias de amor:}

I estrofa: Canten los gozos de amor/ los que sienten alegrías/ y yo las angustias mías,/ pues que siento su dolor./ Y dirélas lamentando,/ con voz de extraña tristura/ ofreciéndolas llorando/ a la perfeta figura/ que siempre estoy contemplando./

II estrofa: La primera angustia siento/ causada del desear/ cuando no os puedo mirar/ sino con el pensamiento./ Pues si es gran padecer/ no veros y contemplaros/ ved cuán mayor debe ser/ cuando yo alcanzó á miraros/ y vos no me queréis ver.

III estrofa: La segunda angustia triste/ siente más el más sufrido,/ porque el gesto va vestido/ de lo que la alma se viste./ Esta es sin comparación/ por sufrir lo que se siente,/ que, si pena el corazón,/ amor escribe en la frente/ de qué pena la pasión.

IV estrofa: La tercera angustia alcanza/ el servidor a la hora/ que conoce en su señora/ ser perdida su esperanza./ Pues mi esperanza perdida,/ ¿quien la perdió como yo? ¿QQuien la tuvo tan sin vida,/ que primero se secó,/ antes que 


\section{Alfonso Colella. Juegos de palabras y múisca en El Cortesano de Luis Milán}

De hecho, en la VI jornada, después de leer todo lo anterior, la imagen de Milán está ya bastante caracterizada. Ya estamos convencidos de que Milán en el palacio del Real no se propone como un simple instrumentista y compositor. El código cortesano dispone que el músico deba ser un entretenedor polifacético. Una figura a caballo entre el músico, el poeta, albiter elegantiarum, el actor e incluso el bufón. ${ }^{6}$ Además, debe saber dominar el arte de la improvisación galante, sobre todo cuando el tañer y el cantar forman parte de los juegos de sociedad e implican comicidad y una cierta ridiculización. ${ }^{7}$

fuese nacida?/

V estrofa: La cuarta por mi dolor,/ que mil veces he gustado,/ es aquel cruel desgrado/ que mostráis con disfavor./ Ora ved qué tal me siento,/ si es firme mi firmeza,/ que con tal conocimiento/ no puede vuestra crueza/ estragar mi sufrimiento./

VI estrofa: La quinta angustia parezco/ de muerto y descolorido,/ que estoy muerto en vuestro olvido/ y vivo en lo que padezco./ ¿Quién se vio tan olvidado/ que ante vos se halle ausente,/ si no yo desesperado,/ en mi mal siempre presente/ y en su presencia pasado?

VII estrofa: La sexta sentí en veros, / que es el temor de enojaros./ Mas, quien no puede ganaros,/ ¿por qué ha de temer perderos? / Quien nunca tuvo favores/ ¿por qué teme disfavor? / ¿Por qué en el trato de amores/ se confia el amador /con sospechas y temores?/

VIII estrofa: La setena y la mayor/ es la angustia del partir:/ joh, cuán grave es de sufrir/ si dejáis competidor!/ Pues si es cosa conocida,/ al tiempo del despediros/ ser gran trance la partida/ más es no poder partiros/ cuando ella está partida./

IX estrofa: He aquí, gentil señora,/ las siete angustias de amor/ que siendos tan servidor/ siento cadaldía y hora./ No me perdí, mas perdí/ en esta triste jornada/ lo que sentiréis de mí:/ siete años te serví/ sin de ti alcanzar nada. [300303]

6 A menudo Milán muestra habilidad, vivacidad de pensamento y gran agudeza en proporcionar motes con los que solucionar los conflictos entre los cortesanos. Su manera de entrar en los diálogos es siempre la misma. Primero formula su máxima en manera seca y luego proporciona anécdotas para demostrar sus ideas. A menudo resulta ser un verdadero juguetón que se basa en la improvisación. A veces la sabiduría de Milán es bienvenida y Diego Ladrón le hace notar que, en lugar de hacer chistes, sería mejor que él compusiera y cantara los sonetos. Hay varios ejemplos donde Milán se presenta como un maître á penser.

Dijo don Luis Milán: -Nadi pierde por otro, sino por sí.[89]

Dijo don Luis Milán: -Pues vuestra excelencia lo manda y estamos en juicio, tengámosle los que habemos de ser juzgados, en ser bien sufridos, que en el lugar de las verdades decir mentiras son maldades.[96]

Dijo don Luis Milán:- El cortesano ha de ser padre de la verdad, hijo del modo, hermano de la crianza, pariente de la gravedad, varón con ley, amigo de limpieza y enemigo de pesadumbre. Y por mostrar cómo lo entiendo, digo, que debe ser tan verdadero como el padre a sus hijos, tratando mucha verdad con ellos para que sean verdaderos, mostrando amor y corrección donde se debe, que en casos hay que si mostrase voluntad sería tenido en poco. Y porque no lo sea, no le han de ver la cara para ser temido, sino obras para ser amado, que no debe causar menosprecio quien ha de ser respetado. Y en todo lo que ha de tratar verdad, ha de ser muy verdadero, sino cuando va de burlas placenero.[120-121]

7 Aunque Milán se describe a sí mismo como un segundo Orfeo, tal vez en broma, en realidad no aparece como músico asalariado. Su función es muy versátil en la corte ducal (Romeu i Figueras 1951: 313-339).

SCRIPTA, Revista internacional de literatura i cultura medieval i moderna, núm. 5 / juny 2015 / pp. 229 - 252 
El comentario del duque sobre la actuación de Milán es el siguiente: ${ }^{8}$

Dixo el Duque: Si tan poca pena diesen en sentirlas como en oírlas, antes serían gozos que angustias, pues tanto alegra vuestra música.[303]

En la proposición del duque, parecen tener la misma importancia el verbo sentir -que hace referencia al impacto emocional que las palabras tienen en el oyente- y el verbo oír -que se refiere a la percepción auditiva (voluptas aurium). Sin embargo, el juicio del duque, por como está formulado, no permite una interpretación inequívoca. Prestamos atención a las palabras de mayor impacto semántico utilizadas por el duque.

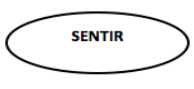

A

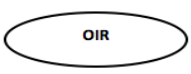

B

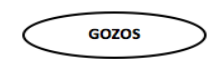

B

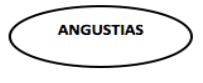

A

\footnotetext{
El polifacetismo se manifesta en El Cortesano como una virtud básica y es muy popular dentro de los códigos de conducta cortesana. Milán a menudo se presenta como poeta-músico y animador experto. Tiene habilidades que hacen referencia a la vivacidad de pensamiento y hace alarde en sus contestaciones de un verdadero dominio de las palabras de doble sentido y, sobre todo, de la antacarnasis.

El polifacetismo es un típico ideal de la cultura renacentista: «Les chantres-improvisateurs qui s'accompagnaint d'un instrument et dont les premiers types furent les trouvères et les ménestrels, nous appaaraissent comme des artistes intégraux: créateurs et exécutants, á la fois poètes (diseurs de rimes), compositeurs, chanteuse, instrumentistes et presque toujours humanistes, ce qui suppose une activité multiforme. Ils jouaient de plusieurs instruments, ce qui suppose une activité multiforme: cette pratique leur venait des ménestrels et des jongleurs» (Haraszti 1955: 15).
}

8 Sabemos que las opiniones estético-musicales del duque son muy importantes en El Cortesano. El duque, debido a sus orígenes familiares (era el hijo primogénito del destronado rey de Nápoles Federico III, nieto de Alfonso el Magnánimo) recibió una sólida formación humanística y tiene una gran familiaridad con la música en general y con la monodia acompañada. La corte del duque de Calabria -única corte estable y no itinerante en España- destaca por su protección y mecenazgo de músicos y literatos. Hay muchos ejemplos de la afición de Fernando de Aragón por la música. En primer lugar, tiene una capilla musical hasta su muerte. Además, el duque puede permitirse el lujo de pagar maestros de capilla de un cierto prestigio, como por ejemplo Juan Cepa por el que pagará 450 ducados al año. También acoge vihuelistas como Luis de Narváez y Alonso Mudarra. Juan de Timoneda alude a la capilla del duque en un cuento suyo: «No había en España quien tantos y tan buenos músicos tuviesse, a causa de los grandes salarios que le daba». (Romeu i Figueras 2003: 421). El duque es tambièn un coleccionista de instrumentos musicales y tiene una biblioteca bien surtida de clásicos (Mcmurry 1977: 23 y Nelson 2004: 194-222). Hay más. El problema de una retórica musical relacionada con el contenido métrico del texto es muy serio en ese tiempo y un poco más de una década más tarde será abordado por Francisco Salinas en la obra De musica libri septem (Gómez Muntané 2012: 135-140).

Sin duda el duque está muy ligado al estilo vocal italiano, basado en la unión entre la música y la letra, sobre todo porque ha recibido una educación humanística en Italia en su juventud (López-Ríos 2008: 127-144). En lo tocante al gusto italianizante propugnado por Fernando de Aragón, casi un reflejo del peculiar gusto que sustuvo Alfonso V en la corte napolitana, véase Fabris (1993: 53-93) y también Romeu i Figueras (1951: 317). 
El texto no deja lugar ninguna critica explícita, peró no hay duda que el duque utiliza una típica estructura de quiasmo que inevitablemente genera un doble sentido y al principio nos hace suponer que en sus palabras hay una crítica enmascarada contra la actuación de Milán. De hecho, el significado que sale recolocando los elementos A y B del quiasmo ( $\mathrm{A}=$ en sentirlas dan angustias; $\mathrm{B}=$ son gozos en oirlas) es ambiguo y puede desplazar al lector contemporáneo que no puede saber si al duque le gusta o no la actuación. Es evidente que un núcleo conceptual anula el otro y viceversa. El juicio del duque se podría recolocar aún así:

oírlas es un gozo, pues tanto alegra vuestra musica

tan poca pena diesen en sentirlas, serían gozos.

Puede parecer descabellado afirmar que el duque desea señalar un conflicto entre música y texto. ${ }^{9}$ Una lectura posible sería pensar que con esas palabras el duque no está criticando a Milán, ni está haciendo observaciones sobre su manera de cantar o tocar. Simplemente, nos dice que si las angustias de amor no fueran un problema real y doloroso, parecerían algo bonito, ya que la música de Milán es preciosa. Se añade el hecho de podernos preguntar por qué Milàn se critica a sí mismo transcribiendo un comentario en torno a su quehacer musical que pudiera hacerle salir "mal parado" como músico. ${ }^{10}$

Otra lectura sería suponer que el juicio del duque sea positivo y que encaja en la casuística de ejemplos legendarios acerca del poder de la música sobre los afectos, sobre el alma y el cuerpo del hombre. Aunque a través de un lenguaje enrevesado, el duque está hablando del proceso homeopático-psicológico de la catarsis aristotélica. Este proceso se produce cuando la música (o el músico) inspira y lleva a un clímax tensiones emocionales asociadas con el dolor. En este episodio la voluptas aurium («pues tanto alegra vuestra música») es la consecuencia de un proceso homeopático.

9 No podemos olvidar que la consistencia entre música y texto es una questión capital de la música del Quinientos, como la de los poderes emocionales de la musica y de sus implicaciones afectivas. Esta coherencia tiene un fundamento aristotélico y aproxima la música a las artes sermoniciales y se ordena en torno al concepto de mímesi y la comprensión de la música como arte afectiva e imitación de pasiones. Giovanni del Lago aconseja hacer la musica che convenga alle parole, Bernardino Cirillo sugiere que la música práctica debe adecuar la cualidad de los intervalos al sentido de los versos, Cochlicus afirma que el músico verdadero es el que conoce los secretos de la imitaciòn y de la adecuación a la palabra (María José Vega, Poética y música en el Renacimiento. La invención del paradigma clásico, en Academia edu (https:// www.academia.edu/1976665/Po\%C3\%A9tica_y_m\%C3\%BAsica_en_el_Renacimiento._La_invenci\%C3\%3n_del_ paradigma_cl\%C3\%A1sico). A los efectos de nuestro análisis, es interesante lo que escribía, a finales de los años 50 del Quinientos Gioseffo Zarlino: «Non sarà adunque conveniente, che in una materia allegra usiamo l'harmonia mesta, i numeri gravi; né dove si tratta materie funebri, et piene di lagrime, è lecito usare un'harmonia allegra, et numeri leggieri, o veloci.che li vogliamo dire. Per il contrario bisogna usare le harmonie allegre, e i numeri veloci nelle materie allegre». (Zarlino 1558: 339).

10 En ElMaestro siempre Milán se presenta como un gran músico. Se leen estos versos: «El grande Orpheo / primero inventor / por quien la vihuela / paresce en el mundo / si él fue primero / no fue sin segundo / pues Dios es de todos / de todo hacedor». (Milán 1976: fol. 6). 
Sea lo que sea, es lícito interrogarse con mayor profundidad sobre la frase del duque. Podemos hacer esto mediante dos tipos diferentes de enfoque: uno musicológico y otro psicológico. El enfoque musicológico mantiene la hipótesis de que en la actuación de Milán hay un conflicto entre la música y el sentido poético. Los problemas que puede haber encontrado Milán en este episodio, como en otros que se desarrollan de forma rápida, se resumen bien en un artículo de Griffiths sobre la canción acompañada (Griffiths 2003). El musicólogo señala que en algunas formas poéticas como el romance resultaba fácil al improvisador del Renacimiento hacer repeticiones melódicas que no correspondían a las formas poéticas y al contenido afectivo de los textos. Probablemente, Milán repite la misma melodía para cada una de las múltiples estrofas y esto se debe a que el texto narrativo es tan extenso que no le es posible elaborar en tiempo real un acompañamiento musical que se adapte perfectamente al texto. ${ }^{11}$ No sabemos si Milán tenía patrones melódico-armónicos particulares o se los inventaba espontáneamente durante sus actuaciones en la corte del duque. De todas formas, come subraya Griffiths, en Suspirantes Baldovinos, un romance ya presente en El Maestro, Milán utiliza una melodía que se puede emplear para cantar cualquier romance sobre cualquier tema y esta melodía no tiene ninguna indicación de ser una línea tallada cuidadosamente, atenta a las necesidades de la canción (Griffiths 2003: 18). El problema está en el hecho de que Milán tiene poco tiempo para comenzar su actuación y, cuando lo hace, participa en un acto que debe fluir sin parar. Aunque se dé cuenta de que algo no funciona, no puede detenerse, ya que debe seguir.

El enfoque psicológico nos da la posibilidad de plantear la cuestión de manera diferente: ¿por qué Milán describe escenas en las que es criticado y desvalorizado, pudiendo haber dado otro giro diferente a las conversaciones que han tenido lugar? Creo que esta pregunta podría explicarse de varias formas alternativas y quizás complementarias. En primer lugar debemos tener en cuenta que la desvalorización es un elemento frecuente en las relaciones sociales dentro de la corte valenciana. Quizás era la manera propia de comunicarse. Varios personajes, y también Milán, son víctimas de juegos utilizando una comunicación ambigua que suscitan la risa. En segundo lugar, hay que considerar que la desvalorización pudiera ser utilizada por Milán como un mecanismo de defensa, de manera que mientras soy yo el que critico, no lo hacen los demás. En tercer lugar la desvalorización también puede ser un "instrumento" para ponerla en palabras de los otros y, después, salir "triunfante", cuando se consige demostrar que los que lo desvalorizaban terminan aplaudiendo su actuación. Algo así como pensar: ahora me criticas, pero yo te haré cambiar de opinión. Entonces, la crítica del duque presente en el texto podría entenderse como un "sacrificio" al que Milán se entrega para después conseguir con más mérito el aplauso (y de hecho es lo que ocurre después, cuando Milán actúa con otra canción).

11 Seguramente, Milán utiliza módulos cuando entona el romance de Durandarte. De hecho, este romance aparece en El Maestro en dos estrofas de ocho versos cada una, mientras que en El Cortesano hace una glosa de un total de 144 versos. Según Gásser, Milán necesitarìa por lo menos 27 minutos para llevar a cabo su actuación (Gásser 1996: 25). El problema de una duración excesiva también surge en la VI jornada, cuando Milán canta 24 sonetos uno detrás del otro. Siempre según Gásser, él necesitaría de una hora, lo que podría ser demasiado para la paciencia de la audiencia. 


\section{Música y juegos cortesanos}

Sin embargo, como adelantábamos en la parte introductoria, la música en aquel entonces era también un pasatiempo pensado para causar la risa de los participantes. A igual que en otras cortes y cenáculos poéticos-musicales que existen en la península y fuera de ella, el palacio del duque es el escenario de una nueva faceta del cortesano que se caracteriza sobre todo como bomo ludens (Bosch Pérez 2009: 64 y Garretas Díez 2012: 163-174). Entonces no se puede excluir que las observaciones del duque sean parte de un juego de doble sentido, planteado a través del contraste entre prótasis y apódosis, que tiene como única finalidad la burla y la diversión. Prueba de ello es la serie de observaciones que hacen los demás personajes que intervienen en la discusión sobre las actuaciones de Milán. En este episodio, por ejemplo, Juan Fernández de Heredia utiliza un lenguaje de doble sentido (doble vínculo, por usar una expresión psicológica) cuando expresa su punto de vista. Afirma y niega a la vez. ${ }^{12}$ Se trata de una manera de divertirse a costa del músico y no tomar una posición precisa. Incluso las mujeres parecen seguir el juego de palabras empleado por los hombres de la corte. El mismo Francisco Fenollet, cuando recita una glosa sobre una canción famosa (De piedra puedo decir), anticipa que su actuación forma parte de un contexto de burla («en este nuestro burlar»). Además, en un pasaje de la II jornada se confirma el aire de charlatanería y de burla que rodea al músico. Doña María se dirige a Milán, en primer lugar para disculparse por el gran ruido que hay en la sala («este descuido que habemos tenido merece ser perdonado»), después formula la petición de escuchar la música de Milán a través de una construcción retórica (antitesis) -la forma más correcta de expresarse en doble sentido-, de la que se puede extraer un hilo de ambigüedad que impide entender si Milán es más apreciado como músico o como entretenedor en la corte. ${ }^{13}$ Habría que tener en cuenta que el esquema música-diálogo, con todo su conjunto de comentarios jocosos está ya presente en la obra de Juan Fernández de Heredia, y que el contexto del juego, en el cual se caricaturiza la música, es un aspecto común en muchas cortes europeas. ${ }^{14}$

12 Acerca de la ejecución de Milán, esto es el comentario de Juan Fernández de Heredia: [...] Parescen gozos, por lo poco que siente angustias de amor don Luis Milán, y no dejan de pascer, por lo mucho que muestra sentirlas cantando, que de amor se va burlando.[303] Parece que Juan Fernández no sólo critica la música, sino que hay una crítica hacia la propia persona del músico, como decir qué sabrás, Milán, acerca de las angustias de amor.

13 Dijo la señora doña María: -Paréceme que convidamos don Luis Milán a una vihuela y dámosle á comer palabras. Callemos, que es gran desacato que su tañer calle por nuestro hablar. Y este descuido que habemos tenido, meresce ser perdonado, pues oyéndole hablar hace olvidar su tañer, y tañendo se olvida su hablar. [150]

14 Con respecto al contexto valenciano, se puede hacer referencia al diálogo dramático La visita de Juan Fernández de Heredia, cuyos protagonistas son los mismos personajes que asisten a las diversiones y a los juegos cortesanos (Fernández de Heredia 1913). En cuanto al contexto europeo y el aspecto multifacético que tenía el juego en aquel entonces, se puede hacer referencia a los manuales del juego que se propagan en Siena, Ferrara y Roma, y las implicaciones que estos juegos tienen con la música (Bargagli 1982). Para toda la cuestión de los juegos musicales, véase Fabris (1996: 213-229) y Haar (1962: 22-34). 


\section{Alfonso Colella. Juegos de palabras y múisca en El Cortesano de Luis Milán}

El juego concebido como un rito de la sociedad es uno de los numerosos aspectos que unen El Cortesano al Libro de motes de damas y caballeros. ${ }^{15}$ Pero, mientras que en el Libro de motes de damas el juego y el entretenimiento venían servidos únicamente en forma de motes, en El Cortesano los mismos aparecen a través de diversas formas artísticas, donde la música juega un papel importante, aunque no exclusivo.

Todo empieza con un mandato improvisado (juego del mandar). Se invita a uno de los participantes -en el caso de Milán se trata de un mandato del duque- a cantar y tocar un tema musical sobre el cual los presentes expresaran su parecer «l'un dall'altro diversamente, e questo al fine di diletto e d'intrattenimento». ${ }^{16}$ No siempre Milán nos da una idea clara de la escena y escenografía en que se desarrollan todos los eventos narrados en El Cortesano, pero tenemos razones para creer que el set design en el que tienen lugar las actuaciones musicales es el mismo en el que se llevan a cabo los divertidos juegos de sociedad. Como en el Juego de naipes de Fernando de la Torre, muy practicado en ese período, probablemente también durante las actuaciones musicales, los participantes se disponían en círculo y de una baraja se extraía una carta que podía tener la petición de cantar algo, obviamente hilarante y sin compromiso. A menudo, entre los libros de juegos cortesanos conservados del periodo que va desde mediados del XV hasta mediados del XVI se encuentran instrucciones exactas. ${ }^{17}$ Por ejemplo, encontramos naipes que exigían cantar a sus destinatarios y el mandato implicaba comicidad y una cierta ridiculización (Bayle-Mouillard 1839). ${ }^{18}$ De aquella misma época hay un juego denominado "penitencia de memorias" que explica lo siguente:

Estas se reducen á canciones, charadas, enigmas, logogrifos en verso, y trozos de poesìa de

15 El Libro de motes de damas y caballeros es la primera obra de Milán que hace referencia al entorno cortesano. Algunos investigadores han llegado a sospechar que el Libro de motes sea una sección extrapolada de El Cortesano publicada en un periodo distinto. De hecho, en El Cortesano se encuentran alusiones a motes citados por las damas y caballeros del Libro de motes. Además, encontramos a menudo las mismas definiciones de los personajes, el mismo empleo de figuras retóricas, los mismos juegos de palabras referidos a protagonistas que aparecen tanto en el Libro de motes como en El Cortesano (García Morales 195: 235 y Vega Vázquez 2006: 24).

16 Esta es una fórmula típica que se repite en los juegos amorosos cortesanos en boga en Italia a principios del siglo XVI (Bargagli 1982: 106 y Fabris 1996: 214).

17 Además de las instrucciones exactas que se conservan entre el Juego de naipes de Fernando de la Torre, encontramos también un bien numero e instucciones, en cierta medida, exactas, en el "Juego de las adormideras" de Lope de Estúñiga y del "Juego Trovado" de Jerónimo de Pinar. Todos estos juegos utilizan la música, asociada con cualquier tipo de forma poética que utiliza recursos estrictamente retóricos, para remedar entretenimientos muy demandados en el ambiente cortesano, como son los juegos adivinatorios o los libros de suertes. Un juego trovado de Jerónimo de Pinar está publicado en el Cancionero General de Hernando de Castillo (1511) y propone a las damas la interpretación de un canto con un tono particular y un animal asociado, que corresponde en el caso de los romances a pájaros (Dumanoir 1998: 112 y Rodado Ruiz 2012: 371-384).

18 Bayle-Mouillard (1839) conserva y recapitula buena parte de los libros de juegos cortesanos del periodo que va desde mediados del XV hasta mediados del XVI. Aquí enumeramos algunos (Bayle-Mouillard 1839: 59, 60 y 64).

18. Haz cuenta que a la almohadilla / estás haciendo labor, / y cántanos con primor / una buena segudilla

22. Una jota cantarás / si sacar tu prenda quieres; y si esto hacer no quisieras / un fandango bailarás.

26. En un almirez sentado, / una aguja enhebrarás, / y entre tanto cantarás / un verso mal entonado

56. De pájaros tomarás / lo que quieras, y armoniosa / una capilla gustosa / de su canto fromarás. 


\section{Alfonso Colella. Juegos de palabras y múisca en El Cortesano de Luis Milán}

conocido talento se les suele mandar improvisar un soneto, decima ó romance sobre algun asunto que se les propone. Convendrá mucho ser breve en el desempeño de cada cosa (BayleMouillard 1839: 168).

También en el juego de El Silvio y de la Caza de Corazones los jugadores forman en rueda y luego uno tiene la tarea de entonar una canción proporcionada (Bayle-Mouillard 1839: 3, 69-70). Si tenemos en cuenta la referencia temporal presente en el mote XVIII, incluido en el Libro de motes de damas y caballeros de Milán, podemos asumir que, a veces, los juegos estaban pensados para ser puestos en práctica por la noche e implicaban el escuchar al músico, cantar y tañer la vihuela. ${ }^{19}$

Por lo tanto, no podemos excluir que en la corte virreinal la música estaba sujeta a las leyes del juego y que, como cualquier otro entretenimiento, no comportaba una atención focalizada, como ya podría ocurrir entre los aficionados de la música a finales del siglo XVIII. ${ }^{20}$ Las actuaciones de Milán se suceden entre murmullos y comentarios expiatorios de unos y de otros. La verdadera involucración emocional de los presentes está, en realidad, en las cuestiones no resueltas entre ellos. Ninguno se conmueve escuchando los romances de Milán, aunque estos sean apasionantes y estén llenos de pathos sentimental. Es indicativo que cuando la discusión se vuelve grave, se hace una petición explícita a Milán para leer el texto poético sin cantar ni tocar. ${ }^{21}$ Esto puede ser un caso aislado, pero normalmente sucede que las actuaciones de Milán se dan como intermedios inseridos entre diálogos y cuentos de contertulios. Por ejemplo, al inicio de la III jornada, en la recitación de un soneto por parte de Milán, se inserta, en medio de pullas entre Milán y Joan Fernández de Heredia. La música llega, después de una petición expresa, para aligerar el tono de la discusión y, por tanto, con una función de desvío. ${ }^{22}$ Siempre en la III jornada el cantar y el danzar se alternan

19« [Dama]: A la noche yo querría/ que cantéis en la vihuela/ Nadie de mi mal se duela,/ pues que todo es alegría. [Caballero]: A la noche cantaré/ Nadie de mi mal se duela,/ pues él mismo me consuela». (Vega Vázquez 2006: 143).

20 Deberíamos añadir a esto el hecho de que el juego en este periodo se considera como un factor importante de la civilización, incluso un símbolo de muchos aspectos de la vida humana. En el ópera de Innocenzo Ringhieri (Cento giochi liberali e d'ingegno, Bologna 1551) veinticuatro personajes resumen todo el universo de la práctica musical del Renacimiento y el mundo mismo se convierte en un símbolo de un juego. Probablemente tendríamos que situar el afán lúdico de la corte valenciana en los términos que señala Innocenzo Ringhieri y que señala Johan Huizinga en su famoso ensayo del 1938 titulado Homo Ludens.

21 Por ejemplo en la IV jornada donde se disputa sobre quién tiene la culpa de la guerra de Troya, los griegos o los troyanos.

Dijo el duque: Señora, no veo el hora cuando oirla, que Joan Fernández me ha dicho que es muy buena. Óyala vuestra alteza y será poner gana á don Luis Milán para decirnos lo que sabe de los troyanos.Y si de lástima vienen las damas a llorar en oir la crueldad que los griegos tuvieron con las damas troyanas, quedarán piadosas, que no podrán reírse de los que matan de amores.Y roguemos á don Luis Milán que lea, que ya está con la obra en las manos, esperando que vuestra alteza se lo mande. [230]

22 Dijo don Luis Milán: -Yo haré lo que mandeis, pues es de buen cortesano que sois, querer que mudemos de

SCRIPTA, Revista internacional de literatura i cultura medieval i moderna, núm. 5 / juny 2015 / pp. 229 - 252 
a coplas de tipo burlesco entre caballeros y damas. Especialmente, en la VI jornada las pullas son parte constitutiva de una larga secuencia de sonetos que Milán entona para responder y defenderse de sus detractores [319-331]. Incluso las coplas de Matalinda y Matacruel brindan un ejemplo de metaliteratura, ya que tratan sobre cómo hacer sonetos. Tenemos que pensar que en la corte virreinal ocurren las mismas cosas que encontramos en Giovanni Boccaccio (Paradiso degli Alberti) y en una novela presente en una obra de Scipione Bargagli. En esta novela, mientras se está hablando de un «gioco della caccia», uno de los personajes, Fulvio, canta una canción a cuyas palabras replican los presentes con comentarios ingeniosos y consideraciones sobre la misma música. ${ }^{23}$

En estos juegos cortesanos, Milán desarrolla un papel activo, no sólo como músico; y a menudo parece ser la víctima de unos juegos que implican una despiadada ridiculización. Por ejemplo, cuando participa en el juego del abejón, que le pone en una situación irrisoria. ${ }^{24}$ En este juego no solo existía la posibilidad de recibir un bofetón en presencia del resto de la corte, sino que el protagonista estaba obligado a divertir a los presentes con la imitación del citado insecto (zun zon). Es evidente que, cuando le pedían jugar, había una voluntad de burlarse o reírse a su costa. Además, Milán es también protagonista activo de otro juego: pasagonzalo, que destaca por su carácter pueril y violento. No sabemos como es la mecánica concreta de este juego: sin embargo, las damas tenían ganas de reírse a costa de los galanes. ${ }^{25}$

\section{Tan poca pena diesen en sentirlas como en oírlas (II)}

Sin embargo, seguimos creyendo que las observaciones del duque, con respecto a la importancia del texto y de la integración entre texto y música, tienen sus razones y reflejan un problema serio.

conversación, que cuando los motes pican, para que no saquen sangre, es bien mudar de nuevas, que el divertir hace vivir. Y oyan el soneto...[161]

23 Bargagli (1587) y Haar (1962). También en muchos tratados europeos de ese período, el conocimiento y la competencia musical son diseminados dentro de los diferentes juegos. La diversión resulta ser la consecuencia de una habilidad en la seducción de los presentes a través de la música, en un continuo «invitarsi l’un l'altro a cantare». (Lorenzetti 2003: 209).

24 Y no os maravilléis si me he destemplado con vos, en sacar vuestras romeras, pues también os destemplastes con don Luis Milán y conmigo, apodándonos a monos, que es un género de milicias que dan un bofetón con un perdón, como este dicho dice: “Al juego del abejón/ parece el muy mal burlar:/ perdón piden para dar/ un bofetón”.[288]

Este juego es mencionado varias veces a lo largo del Cortesano y debía tener ya cierta antigüedad, pues aparece recogido en el Vocabulario español-latino de Antonio de Nebrija de 1495 (Vega Vázquez 2006: 177). También el Libro de motes de damas y caballeros recoge el juego de abejón (mote XXXIV): «[Dama] Levantaos con dos otros,/ y los tres sin lisión,/ jugaréis al abejón. [Caballero]: L’abejon ¿`sabéis qué dize/ cuando él hace “zun zon”?/ Que las damas falsas son». (Vega Vázquez 2006: 177)

25 Don Diego Ladrón, que vio escaramuzar a motes a don Francisco y a Joan Fernandez, entró en la escaramuza y dijo: - ¿Jugáis á pasa Gonzalo? Señores, decídnoslo, que también jugaré yo, si Joan es el Gonzalo. Don Luis Milán atravesó como a valedor de Joan Fernández, y mostrando defendelle le hirió sin sacar sangre, y dijo: -Dejad vos ese mi Joan, que no sufre papirote, sino á quien le da en el mote,más del palo que del pan. [75] 


\section{Alfonso Colella. Juegos de palabras y múisca en El Cortesano de Luis Milán}

Aunque no de forma explícita, el duque podría hacer referencia a la teoría de los "afectos" y a toda una tradición humanística que ya desde el periodo de Alfonso el Magnánimo tiene como modelo el canto clásico acompañado de un solo instrumento. ${ }^{26}$ En este periodo, esta tipología ejecutiva es prerrogativa de músicos y poetas improvisadores que tienen sus raíces en la cultura humanista cortesana y en la tradición popular. Es suficiente pensar en la heterogénea colocación de Benedetto Gareth (c. 1450-1514) y de Serafino Aquilano (c. 1466-1500) en la corte aragonesa de Nápoles. ${ }^{27}$

Sin embargo, más allá de los problemas de interpretación y técnica que pueda haber hallado para cantar Las siete angustias de amor, Milán definitivamente no está en condiciones de diseñar, a priori, su improvisación. Cualesquiera que sean las expectativas del duque, la fusión entre música y palabra debe realizarse en tiempo real, entre un diálogo y el siguiente. A menudo en El Cortesano el tiempo apremia y el músico debe confiar en la inmediatez del instinto. Por si fuera poco, todo se complica aún más por las demandas repentinas de su público femenino. Frecuentemente se forman grupos de oyentes en círculo que quieren escucharlo tocar. El músico se muestra con pasividad y sumisión,

26 La tradición del canto acompañado (laúd o vihuela) está muy extendida en la Corona de Aragón, y especialmente en el reino de Nápoles se encuentran grandes intérpretes que giran en torno a la corte y frecuentan los círculos humanistas. Nápoles, en la época de Alfonso el Magnánimo, es un cruce de experiencias literarias y musicales. La corte es frecuentada por Benedetto Gareth, Pietro Aretino, Antonio Beccadelli, Bartolomeo Fazio, Jacopo Pontano, Jacopo Sannazzaro. Además está generalizada la afición por el canto. Johannes Tinctoris en su De natura et proprietate tonorum alaba su alumna, la princesa Beatriz, hija de Fernando I, porqué tenía una pronuncianión excelente (Pope 1961: 371).

27 En realidad la canción acompañada ya había desempeñado un importante papel en El Maestro de Milán. Esta obra consiste en cincuenta piezas para vihuela sola y veintidós canciones (villancicos, romances y sonetos) con acompañamiento de vihuela. Todas las piezas del volumen se conciben como un punto de partida para que el intérprete realice una aproximación personal a las obras (improvisación), para que las haga suyas y les imprima su personalidad. La creación y ejecución de cada pieza estaban, según la visión de Milán, indisolublemente entretejidas. Como ya señaló Arriaga, las canciones acompañadas de vihuela constituyen la parte más original de la obra ya que reflejan el intento de formalizar, a través de la escritura musical, una modalidad de ejecución (el canto acompañado de la vihuela) muy difundida en el mundo de los improvisadores que ya en la segunda mitad del XV actuaban en la cortes españolas e italianas, sobretodo la napolitana que ya desde el periodo de Alfonso el Magnánimo se modela como una derivación política, cultural y musical de la hegemonía castellano-aragonesa (Arriaga 2007: 6-35).

En las cortes del norte de Italia destacan improvisadores como Pietrobono "el primo cithareo" descrito por Antonio Cornazaro y Paolo Cortese como cantante solista que se acompaña por su "cetra". Podemos añadir una larga lista de "cantori a liuto". Se aprecia uno de los más grandes poetas de la corte de los Medici a finales de los "400, Antonio di Guido porque cantaba sus poemas acompañándose "a liuto" o "alla viola” o "alla lira”. Angelo Poliziano cita varias veces este modo de ejecución en las epístolas que describe los éxitos de su discípulo Pietro dei Medici. Lo mismo Poliziano quien elegirá una muerte paradójica al decidir pasar los últimos momentos de su vida cantando y acompañándose con el laúd. Bernardo Accolti canta y acompaña a sus "strambotti" con un instrumento de cuerda: «[...] Of Pietrobono not a note of written music is preserved, yet he is beyond doubt one of the most important figures in all of fifteenth music, certainly in Italy» (Lockwood 1984: 98). Véanse también: Atlas (1985: 102), Lanza (1973), Pirrotta (1984: 91), Pèrcopo (1892), Menghini (1894) y Haar (1989: 240-266). En cuanto a España, es importante el trabajo de Emilio Ros-Fábregas sobre el poeta y vihuelista andaluz Garci Sánchez de Badajoz, que, según el estudioso, merece dentro la tradición musical no escrita el mismo lugar reconocido a Pietrobono del Chitarino (Ros-Fábregas 2003: 55-75). 
porque esto entra en los códigos de la vida de la corte y no son raros los casos en los cuales Milán parece un monigote, una persona a merced de los demás, que provoca la risa y la diversión de las ociosas damas de la corte de Fernando y Germana. Aunque el texto de El Cortesano a menudo carezca de relaciones semántico-temporales, tenemos la impresión de que los eventos musicales nazcan de un ex improvviso de continuas peticiones. Si Milán se expresase con una prosa más precisa y copiosa en conexiones semánticas, su obra estaría repleta de las mismas locuciones adverbiales que abundan en la literatura de la improvisación entre los siglos XV y XVI. ${ }^{28}$ Muchas veces, Milán se describe a sí mismo como un torbellino sin tiempo material para una planificación escrupulosa de los ritmos de su actuación. Sus manos probablemente no siempre estén preparadas para los pasajes de virtuosismo. ${ }^{29}$

\section{Parecen gozos por lo poco que siente angustias de amor don Luis Milán}

El hecho es que las observaciones del duque siguen las del poeta y escritor de corte Joan Fernández de Heredia. Milán y Fernández tienen una relación de amistad, a veces con incrustaciones de envidia. Ambos se disputan la simpatía del duque:

Respondió Joan Fernandez: Señor, el uno y l'otro creo que son, parecen gozos por lo poco que siente angustias de amor don Luis Milán, y no dejan de parecer por lo mucho que muestra

\footnotetext{
28 En muchos textos literarios entre ‘ 400 y ‘500, los significantes lingüísticos que se refieren a las técnicas de improvisación se van organizando por primera vez como frases adverbiales y más tarde como verbos y sustantivos. Entre las frases adverbiales más utilizadas se encuentran los siguientes: d’improvviso, ex tempore, ex improvviso, alla sprovveduta, á l'impourvue, unexpected, sortisatio (Caporaletti 2005: 119). Poetas y músicos como Serafino Aquilano, los hermanos Brandolini y otros, están inmortalizados en el acto de improvisar versos "all’improvviso" que a veces pueden ser un poco "grossolani”, según el juicio de Lodovico Dolce y de Apostolo Zeno (De Rosa 1834: 65).

En al poesía de improvisación que se propaga en España a partir del 500 hasta el 700 dominan los términos: de repente, de improviso, echar coplas de repente, trovar de repente (Del Campo Tejedor 2004: 119-157).

29 El hecho de que Milán esté involucrado en una serie muy rápida de eventos y cambios de escena y deba asegurar la disponibilidad constante de acuerdo a las peticiones del duque y todo el entourage de la corte. Está atestiguado por frases como las siguientes:

Respondió don Luis Milán: Señor Joan Fernandéz, si la dama que la señora doña Hierónima, vuestra mujer, ha dicho, lo manda, mis coplas saldrán.[74]

Que si gana os torna de tañer y cantalle, aquí tengo una muy buena vihuela y damas que os escucharán, que están en visita con doña María mi mujer.[145]

Que si don Luis Milán quiere echarle de aquí, taña un poco, que no faltará el demonio de la envidia que alguno terná a su música.[294]

Dijo don Diego Ladrón: -Si los cantáis, sean por don Pedro Milán, y gozos nos parescerán, pues su alteza os hará mucho favor, cantando por su servidor.[304]

Leonor Gálvez [...] habló a voluntad de todas, y dijo: -Ya que en jubileo de música nos hallamos, pues por jubileo se deja oír don Luis Milán.[313]

Dijo la reina:- Don Luis Milán, por vida de Matalinda y Matacruel, que cantéis las coplas que por esto hecistes, y de palabra nos contéis la historia. [331]
} 


\section{Alfonso Colella. Juegos de palabras y múisca en El Cortesano de Luis Milán}

sentirlas cantando que de amor se va burlando. [297]

Prácticamente, Joan Fernández de Heredia pone en duda la sinceridad de los sentimientos de Milán, que en el fondo no está autorizado a hablar de amor ya que en la corte se presenta como un seductor que coquetea con todo el universo femenino (Perugini: 2012). Pero, más allá de lo que podría parecer el tema habitual de la hipocresía en el cortejo amoroso, tema del que ya el Libro de motes de damas y caballeros recoge muchas variantes y que ya había sido abordado en tradiciones poéticas anteriores, lo más interesante es que Joan Fernández de Heredia se enfada con Milán porqué este parodiaba las maneras poéticas. Toda la experiencia literaria y poética de Milán, desde la publicación de su Libro de motes de damas y caballeros, además de ser desvalorizada y desacreditada, también es juzgada por Joan Fernández de Heredia como la irrupción de un músico en el campo de la literatura y esto es aun más inaceptable, si se considera que Milán no conoce el latín. ${ }^{30}$ No se trata de una polémica limitada al perímetro de una relación de amistad un poco enfrentada. La cuestión planteada por Joan Fernández de Heredia es bastante delicada y aparece también en El Cortesano de Castiglione, donde Federico Fregoso se dirige a un músico que abandonó la música para dedicarse a la poesía. En cierto momento, Fregoso señala que el músico en cuestión había perdido sus habilidades musicales y que él solo pensaba que sus versos podrían tener un valor artístico. ${ }^{31}$ Unos años antes, en un pasaje de Las Obras, Joan Fernández de Heredia había expresado su desconfianza hacia las habilidades poéticas de Luis Milán, que considera sinceramente flojas y muy inferiores a su arte en la vihuela. ${ }^{32}$

Pero lo que puede parecer una incompetencia, tal vez puntual, al mezclar satisfactoriamente el texto con la música, también podría ser visto como una cuestión compleja relacionada con la propia práctica de la improvisación. ${ }^{33}$ Es obvio que hay límites inherentes a la práctica de la improvisación

30 «Si la vihuela oluidays,/ y trobays y componeys,/ tomays lo que no sabeys/y lo que sabeys dexays,/ y ansi señor os perdeys:/ Dexaos de trobar en fin,/ nos metays mas en tal trance,/ qu'un podenco's dará alcance,/ y pues no sabeys latín/ quieros trobar vn romance». (Fernández de Heredia 1913: 196-197).

31 Federigo Fregoso: «[...] e per confirmazion di questo, io conosco uno eccellentissimo musico, il qual, lasciata la musica, s'è dato totalmente a compor versi e credesi in quello esser grandissimo omo, e fa ridere ognun di sé e omai ha perduta ancor la musica. Un altro de' primi pittori del mondo sprezza quell'arte dove è rarissimo ed èssi posto ad imparar filosofia, nella quale ha cosi strani concetti e nove chimere, che esso con tutta la sua pittura non sapria depingerle. E di questi tali infiniti si trovano. Son bene alcuni, i quali, conoscendosi avere eccellenzia in una cosa, fanno principal professione d'un'altra, della qual però non sono ignoranti; ma ogni volta che loro occorre mostrarsi in quella dove si senton valere, si mostran gagliardamente; e vien lor talor fatto che la brigata, vedendogli valer tanto in quello che non è sua professione, estima che vaglian molto piú in quello di che fan professione. Quest'arte, s'ella è compagnata da bon giudicio, non mi dispiace punto». (Castiglione 1947: II, 39). Véase también Haar (1983: 179).

32 «Si la vihuela olvidays, / y trobays y componeys,/ tomays lo que no sabeys/ y lo que sabeys dexays, y ansi señor os perdeys...» (Fernandez De Heredia 1913: 196). En el Proceso de coplas de burlas (ms. 2050 de la Biblioteca de Catalunya) se encuentra el informe de la disputa poética que protagonizaron Juan Fernández de Heredia y Luis Milán, incluyendo composiciones inéditas de ambos (Villanueva Serrano 2011: 61-118).

33 Tiene que ver con un enfoque amateur difundido en las artes en aquel período. Por lo que podía resultar de moda presumir de competencias musicales y, aun más, resultar distintivo y fascinante presentarse como un escritor de versos. Por otra parte, el modelo ideal de un hombre de cultura renacentista es polifacético, el artista debe tener competencias

SCRIPTA, Revista internacional de literatura i cultura medieval i moderna, núm. 5 / juny 2015 / pp. 229 - 252 
que a menudo hacen que sea imposible satisfacer la legítima demanda del duque. ${ }^{34}$ Debemos observar que ya en el periodo en el que está escrito El Cortesano de Milán, el problema de vincular el texto a la música es algo muy importante y una habilidad poco frecuente. De hecho, se trata de la cualidad que más impacta a Angelo Colotio cuando escribe la Apologia di Serafino Aquilano. ${ }^{35}$ Además, las anotaciones del duque sobre la fractura entre el texto y la música ya habían sido objeto de reflexión por parte de la generación anterior de compositores cortesanos en activo en las décadas de 1470 y 1480 cuya música muestra cierta independencia con el texto de tal forma que oscurece el significado de la letra. En este contexto, Juan de Encima propuso una técnica personal que, a través del uso de modelos esquemáticos, contemplaba una relación más estrecha entre música y texto. De de acuerdo con los preceptos de Juan de Encima, el músico debería haber comenzado cada frase musical monofónicamente con un tratamiento silábico del texto, y más tarde tendría que aumentar su movimiento, posiblemente con un breve melisma en la penúltima silaba con objeto de preparar el retardo que delineaba claramente el final de la frase musical y de la poética (Knighton 2001: 157). ${ }^{36}$

Si hemos de confiar en el duque y en sus observaciones sobre la actuación de Milán, así como en las crítica reiteradas de Joan Fernández de Heredia sobre el diletantismo literario de Milán, hemos de concluir que las actuaciones de Milán tenían carencias, no directamente relacionadas con sus habilidades, que son indudables; más bien, con la práctica generalizada en aquel tiempo, de acompañar sonetos, romances y coplas utilizando esquemas armónico-melódicos fijos y preconcebidos (Fiorentino en prensa). Y es que no debe olvidarse que Milán está profundamente inmerso en esta tradición que tiene una fuerte relación con la música popular. De hecho, las melodías cantadas/recitadas y acompañadas de vihuela que se desarrollan en El Cortesano no se sustentan en ningún soporte de notación escrito y no son parte de una trayectoria compositiva premeditada. ${ }^{37}$

sea musicales que retóricas. Hay que tener presente que la competencia vocal está siempre en simbiosis con actitudes literarias desde el momento en que comporta el conocimiento de textos, la búsqueda de un compás rítmico y una combinación entre palabra y ritmo.

34 En lo que respecta al aspecto teórico, el problema será abordado por la Camerata Florentina y en particular por Gioseffo Zarlino en el pasaje donde se dice que más allá de los instrumentos involucrados en el acompañamiento y más allá del hecho de que un texto sea cómico o trágico, la regla general es que el cantante respecte la entonación sentimental. Ya estamos muy cerca de la teoría de los afectos, a los que apela Bardi en el Dialogo della musica antica de Vincenzo Galilei, cuando dice que el poeta no debe separarse de la música y viceversa (Zarlino 1558 y Gásser 1996: 30)

35 «Cercava concordare le parole al leuto per imprimerle nell'animo delle genti e per hor infiamare hora remectere». Este aspecto viene confirmado por Vincenzo Calmeta, secretario de Beatrice Sforza, que afirma en los siguientes términos: «Nel recitare de' suoi poemi era tanto ardente e con tanto giuditio le parole con la musica consertava che l'animo de li ascoltanti o dotti o mediocri o plebei o donne equalmente commoveva» (Torrefranca 1939: 319).

36 Como ya lo habían notado Higinio Anglés y Menéndez Pidal, en los siglos XV y XVI los músicos, habitualmente, se doblegan al "señorío de la letra", la cual se entiende como rectora de la expresividad musical (Menéndez Pidal 1968: 378 y López Alemany 2000: 139-154).

37 Van Der Werf ha estudiado toda una serie de esquemas melódico-armónicos no improvisados ex novo, pero que forman parte de un modelo ya existente en la época medieval (Van Der Werf 1972: 63-70). 
Milán no utiliza melodías y armonías compuestas ex novo para la ocasión, sino más bien melodías del repertorio esquemático preexistente y de tradición oral, de acuerdo con una práctica similar a la típica del canto llano litúrgico. En este caso, la habilidad de Milán como intérprete e improvisador se encuentra en la capacidad de adaptar el material de partida a la realidad formal y semántica del texto poético que está cantando. Se trata de una práctica que tiene todas las características de los contrafacta (disfraz poético de una melodía preexistente), ampliamente utilizados en el canto llano litúrgico y en todos los repertorios poéticos que se basan en esquemas métricos regulares y, sobre todo, estróficos. Se toca la misma melodía, no sólo en diferentes estrofas del mismo texto, sino también en textos completamente diferentes. ${ }^{38}$

En El Maestro Milán incluyó veinte canciones para voz y vihuela. Aunque la fusión entre música y texto de hecho se había traducido necesariamente en un trabajo de diseño a priori, sin embargo, las canciones incluidas en esta obra no son el resultado de un proyecto de formalización y composición de acuerdo con el sentido moderno del término. En el centro hay siempre la capacidad para improvisar y, sobre todo, incitar a la improvisación. ${ }^{39}$ Como en cualquier recorrido autodidacta, el oído tiene su parte central («siempre he sido tan inclinado a la música, que puedo afirmar y decir que nunca tuve otro maestro sino a ella misma»), pero es esencial la repetición y la memorización de fórmulas armónicas y patrones de acordes. Todo esto se lleva a cabo fuera de los procesos de aprendizaje visuales, basados en el ciclo de lectura-escritura. En efecto, se puede apreciar el enfoque autodidacta de Milán en todas las composiciones de la colección. Como señala Griffiths, el estilo es siempre crudo y poco refinado, siempre hay una falta de complejidad en el ajuste de las partes. ${ }^{40}$

Los límites de este enfoque esquemático y de improvisación emergen claramente en la adaptación musical de un soneto de Jacopo Sannazzaro, O gelosia di amanti. Lo que a primera vista podría parecer una composición de antemano, en realidad revela cuáles son las estrategias y también los límites en los que opera, por experto que sea, un improvisador. Milán recupera un esquema armónico y melódico, Guárdame las vacas, ya muy conocido en su tiempo, con el cual resuelve el problema armónico y melódico. Sin embargo, el análisis formal que ha hecho Griffiths demuestra

38 Una técnica basada en un principio similar, pero opuesto, es la que se describe en la baja Edad Media por los teóricos como Aegidius de Murino, que había dado instrucciones precisas sobre cómo disfrazar una música existente, por ejemplo un motete, con nuevas palabras (De Murino 1864-67: 125 y Haar 1986: 16-17).

39 «El autor [Luis de Milán] afirma que sus obras son "e la vihuela sacadas y escritas”, probablemente indicando que son improvisadas y luego pasadas a notación. Las fantasías están elaboradas según una misma fórmula que el autor desarrolla con gran variedad e ingenio, algo parecido a un discurso de alto nivel retórico en el cual se desarrolla una serie de temas inde $\neg$ pendientes con suma coherencia narrativa y dramática». El autor [Luis de Milán] afirma que sus obras son «de la vihuela sacadas y escritas», probablemente indicando que son improvisadas y luego pasadas a notación (Griffiths, Luis Milán, en «Semblanzas de compositores españoles», 14, pp. 5-6 (consulta on line http://recursos.march. es/web/musica/publicaciones/semblanzas/pdf/milan.pdf)

40 Milán se sitúa históricamente entre el estilo improvisatorio de los laudistas de Petrucci y Attaingnant, y el estilo técnicamente más maduro de la generación de Francesco da Milano (Ward 1953: 161). También Arriaga sugiere la posibilidad de una procedencia e influencia norditaliana y francesa en el estilo de Milán (Arriaga 2008: 9-27). 
claramente que no hay correspondencia formal entre las repeticiones musicales y el texto de Jacopo Sannazzaro, ya que en diferentes puntos su melodía no se adhiere a la estructura poética (Griffiths 2003: 20). Durante los años en los que Milán frecuenta la corte valenciana, existen diversas melodías y patrones armónicos que son adaptables a diferentes poemas. Según Francisco Salinas, estas melodías basadas en patrones armónicos fijos se adaptaban bien a los versos octosílabos que tenían que entonarse y utilizarse para las narraciones épicas y liricas. Salinas da el ejemplo del esquema melódico del Conde Claros (I-IV-VI, de forma similar a la Bergamasca en Italia) que los españoles utilizaban para cantar varios romances. En los libros de frottole impresos por Ottaviano Petrucci, a principios del '500, hay una docena de modelos musicales para poesía llamados modi o arie destinados a la entonación de cualquier soneto -véase por ejemplo el Modo di cantar Sonetti-, incluidos en el libro cuarto. Como ejemplo del mundo de los laudistas, se puede citar una recopilación antológica de Raffaello Cavalcanti que se caracteriza por ser tanto una síntesis útil para el solista de laúd, como una colección de canciones cantadas con una sola voz y acompañadas por un instrumento. En esta silloge las canciones tituladas "aria da cantare", "aria alla siciliana" o "aria per istanze" son parte de la tradición de improvisación del Renacimiento (Coelho 1995: 423-442 y Haar 1981: 31-46). En estas colecciones, como suele ocurrir entre los cantori a liuto, el acompañamiento no está escrito y es de carácter esquemático. Además, el modo interpretativo del cantare a stanze, que viene de improvisadores que en Italia resumen en una sola persona la poesía y el canto, recuerda lo que realmente hace Milán en la corte de Valencia, cuando debe cantar con la vihuela textos que se caracterizan por cierta regularidad métrica. ${ }^{41}$

\section{Cantéis sonetos vuestros, porque gustemos de los sonsonetos...}

Sin embargo, en un cierto momento de este largo apartado diálogico-musical y dramático, en el que hemos decidido hacer nuestras consideraciones, entran la reina Germana de Foix y las damas para asistir al concierto de Milán. Doña Leonor, guía de la gala, invita a Milán a cantar sonetos escritos por él mismo. ${ }^{42}$

\footnotetext{
41 Por lo que respecta a los textos que se sometieron a un tratamiento musical de carácter esquemático, hay que distinguir entre dos tipos: los que se toman de una tradición o de colecciones tales como los romanceros, y los improvisados. El término cancioneros, como sabemos, implica una fuerte relación entre el texto y la música y de esto tenemos una clara indicación en un broadsheet del poeta valenciano Juan Timoneda, contemporáneo de Milán (Rodríguez-Moñino 1967: 563). Además, en el Cancionero General encontramos Las Siete Gozos de amor de Juan Rodríguez de Padrón y muchas instrucciones de cómo tiene que ser cantado el poema. Varios fragmentos poéticos de origen popular que se incluyen en los romanceros, como baladas y villancicos, se adaptan, modifican y acortan para ajustarse como comentario poético-musical a los diálogos que tienen lugar entre los personajes. Los más importantes son Más querría ser vos conde, Sospirantes Baldovinos, Fuente fria, fuente fria, Más pesar de vos. Aunque se podrian citar muchos más ejemplos.
}

42 Las damas de la reina vinieron, que la señora doña Leonor Gálvez, que es guión de la gala, habló a voluntad de 
Más allá de lo que son las estrategias retóricas utilizadas por doña Leonor para formular la petición, como el uso de la antanaclasis caracterizada como la repetición del vocablo mandar en acepciones distintas, siempre entre el juego del doble sentido, aquí parece que las cosas cambian. Las mujeres parecen mucho más interesadas que los hombres en escuchar a Milán («por jubileo se deja oír Luis Milán»), y también lo estará el duque. Doña Leonor, tras los preámbulos de cortesía, hace una petición explícita: «cantéis sonetos vuestros, porque gustemos de los sonsonetos, que nos harán bien callar y mejor cabla para entendellos». La contestación de Milán, además de estar destinada a halagar y a hacer reír a las damas a través de un dominio de las palabras, ${ }^{43}$ demuestra también el grado de servidumbre del músico. Está claro que su actuación está sujeta al mandar de las damas. ${ }^{44}$

Varias son las estrategias retóricas utilizadas por Milán para legitimar su exhibición y su papel de músico en la corte. Seguramente, el principio general en el que se inspira está ya presente en la introducción de El Cortesano: «Da modos y avisos de hablar sin y verbosidad, ni afectación, ni cortedad de palabras, que sea para esconder la razón, dando conversaciones para saber burlar a modo de palacio».[63]

Los aspectos que más sorprenden en esta declaración, que está evidentemente en línea con los modelos de comportamiento de la corte establecidos por Castiglione, son la brevedad (sin verbosidad) y la espontaneidad (ni afectación). Es evidente que se trata de actitudes que forman parte del área semántica de la sprezzatura, y tienen una importancia principal en los códigos de conducta cortesana. ${ }^{45}$ Después de este procedimiento de legitimación de la música y de autolegitimación

todas, y dijo: -Ya que en jubileo de música nos hallamos, pues por jubileo se deja oir don Luis Milán, las damas quieren mostrar que de sabio es no mandar el mandador, que mandado es muy mejor, como veremos en vos, que os dejaréis mandar de las damas en dalles quanto os pedirán.Y la primera quiero ser yo, que os mando me cantéis sonetos vuestros, porque gustemos de los sonsonetos, que nos harán bien callar y mejor hablar para entendellos.[313]

Por lo que respecta a la reina Germana de Foix, sabemos que ella misma toma parte activa en los entretenimientos lúdicos desarrollados en su corte. De ella hablan como una mujer con carácter festivo, desenfadado y tendente a la diversión y al juego (García Mercadal 1942: 48, 97 y Ríos Lloret 2003: 196 y 219).

43 Es de notar que en las partes introductorias del soneto, Milán le da la vuelta, con mucha habilidad e ironía a la crítica que Leonor Guálvez le hace:

Don Luis Milán respondió: Señora doña Leonor, si por jubileo ne dejo oír, no se maraville vuestra merced, pues por jubileo se dejan ver las damas y no para sacar almas de pena.[313]

44 Don Luis Milán respondió:[...] Por donde, siguiendo yo sus pisadas, no me perderé, que no es bién dejar pisar lo que debe estar en pie. Yo no soy tan desmandado de no dejarme mandar donde soy muy bien mandado. Y pues aquí está mi palomando, que mandar me puede, yo me doy por mandado.[313-314]

Siempre en el mismo contexto:[...]La mejor respuesta que se puede dar: obedecer a buen mandar. Y empezó a cantar este soneto (4.7): Si voluntad merece ser pagada/ por cual razón no soy de esto pagado?/ Diréisme vos:'Pues has mal deseado/ mal desear, págalle con no nada"./ Respondo yo, que es muy perjudicada/ mi gratitud, que nunca os ha enojado.// Responderéis que debe ser juzgado/ lo que sin ley no es cosa bien juzgada./ Si fuese yo juez de esto, aunque soy parte,/ con gran razón daría ley en esto,/ que lealtad gran lealtad merece./ Pues buen amor no tiene ningún arte,/ y en bien amar a todos ganó el resto:/ quien meresció, jamás no desmerece.[315]

45 El duque aprecia la previsión de la respuesta de Milán a las damas. De hecho, en seguida dice: -Bien muestra en su 


\section{Alfonso Colella. Juegos de palabras y múisca en El Cortesano de Luis Milán}

del músico, construido por la sabiduría retórica y la inteligencia cortesana, la perplejidad y el comportamiento general de los presentes se vuelve más benevolente. Es la reina quien desbloquea la situación, exponiendo una relación necesaria entre la música y la caballería:

La reina dijo: -Don Luis Milán tiene razón, que cuando la música es de caballero, hase de escuchar, si ya él no quiere hablar. [319]

Al mismo tiempo Milán recibe el reconocimiento de su entorno, no ya sólo entre las mujeres, sino incluso entre los propios compañeros. Entonces, Milán comienza una actuación con una serie de veintiocho sonetos entremezclados, con comentarios de las personas presentes, relacionados con el contenido temático de los sonetos. ${ }^{46}$ Se trata de una exhibición muy larga -probablemente dure una hora. Frente a las damas ahí reunidas para escucharle, Milán, como un perfecto galán, no escatima esfuerzos. Según el código nobiliario, el músico y también cortesano debe comportarse de manera profusa y desprendida y tiene que acatar el hecho de verse juzgado no solo en función de su música, sino también de sus méritos corteses y de su disponibilidad a someterse al juego del mandar conducido por las mujeres.

Pero hay que tener presente que, en esta circunstancia. la forma poética en la que Milán tiene que adaptar su música no es aquella de Las siete angustias de amor, sino también aquella del soneto. Sabemos que el soneto es una forma particular que admite pocas posibilidades de repetición, debido a su concisión textual y a las interrelaciones internas entre imágenes e ideas. Si antes el duque podría haber notado una fractura entre música y texto, podríamos imaginar que también esta vez, dada la dificultad que comporta el acompañamiento músical de un soneto, vuelva a proponer la misma cuestión. En cambio, el juicio del duque, en esta ocasión, nos sorprende a todos. Parece satisfecho con la exhibición de Milán, tanto que le pide continuar, aunque el músico esté cansado. ${ }^{47}$

El duque, entonces, se está divirtiendo, como también lo están haciendo los demás que lo escuchan. Especialmente, Diego Ladrón y Francisco Fenollet. No cabe duda de que aquello que podría parecer

hablar don Luis Milán que los milanes vinieron de los griegos, con Hércules en Italia: pues habla con la brevedad de ellos, como agora ha dicho en este vocablo, "palomando", queriendo decir palo y mando. [314].

Después de los cumplidos del duque, Milán empieza a cantar sonetos. Su actuación es, como dice él mismo, «un obedescer a buen mandar». Lo interrumpe durante sus actuaciones Diego Ladrón, definido como un estorbamusica, pero en ese momento Milán ya se siente respaldado por el juicio de las damas y del duque. Sus sonetos sirven para acallar las voces de los presentes, como atapabocas.

46 Milán comparte con el duque el gusto por la poesía y las formas poéticas de origen italiano. Además, la presencia de sonetos (tres sonetos italianos de Petrarca y uno de Sannazaro) en El Maestro, y de citas de Petrarca, tanto en El Maestro como en El Cortesano, testimonia que la corte de Valencia en aquellos años era un centro italianizante (Meregalli 1988: 65).

47 Dijo el Duque: -Don Luis Milán, si os cansáis de cantar, no os canséis de contar más sonetos, que no son para cansar los graciosos sonsonetos.[334] 
una crítica del duque con respecto a Las siete angustias de amor, y que nos ha inducido a indagar las causas, utilizando categorías musicológicas, antropológicas y psicológicas, no es en realidad una crítica. Incluso el duque, de hecho, se expresa con el lenguaje del doble sentido que forma parte del juego cortesano. Por un lado parece querer expresar juicios serios, pero por el otro, en cambio, bromea. Así, sólo podemos reforzar nuestra hipótesis inicial de que la música está insertada en los códigos nobiliarios de diversión en la corte, y que todo aquello que tiene que ver con la música, tiene también que ver con la diversión, la broma y la burla. 


\section{Bibliografía}

Arriaga, Gerardo (2007) «Reflexiones en torno a Luis Milán: Vida, obra, historiografía», Roseta. Revista de la Sociedad Española de la Guitarra, pp. 6-35.

Arriaga, Gerardo (2008) «Luis Milán, poeta y compositon», en F. Roa (ed.) Libro de música de vibuela de mano intitulado «El maestro», Madrid, Sociedad de la Vihuela, pp. IX-XXVII.

Atlas, Allan W. (1985) Music at the Aragonese Court of Naples, Cambridge, Cambridge University Press.

Bargagli, Girolamo (1982) Dialogo de' giochi che nelle vegghie sanesi si usano di fare (1572), ed. Ermini P. D’Incalci, Siena, Intronati.

Bargagli, Scipione (1587) I trattenimenti di Scipione Bargagli, dove da vaghe donne e da giovani huomini rappresentati sono honesti e dilettevoli giuochi, narrate novelle e cantate alcune amorose canzonette, Venezia.

Bayle-Mouillard, Elisabeth (1839) Manual completo de juegos de sociedad o tertulia, y de prendas, Madrid: Norberto Llorenci.

Bosch Pérez, Estela (2009) Los valencianos del Cancionero General: estudio de sus poesías, Valencia, Publicacions Universitat de València.

Campo Tejedor, Alberto del (2004) «Trovadores de repente. La improvisación poética en el Siglo de Oro», eHumanista, vol. 4, pp. 119-157.

Caporaletti, Vincenzo (2005) I processi improvvisativi nella musica: un approccio globale, Lucca, Libreria Musicale Italiana.

Castiglione, Baldassar (1947) Il libro del Cortegiano (Venezia 1528), ed. Vittorio Cian, Firenze, Sansoni.

Coelho, Victor (1991) «Raffaello Cavalcanti's lute book (1590) and the ideal of singing and playing» en Jean Michel Vaccaro (ed.) Actes du XXXIV Colloque International d'Études Humanistes. Centre d'Études Supérieures de la Renaissance (Tours, 1-11 julio, 1991), 1995, pp. 423-442.

Cruilles, Marqués de (2007) Noticias y documentos relativos a doña Germana de Foix, última reina de Aragón, ed. Ernest Belenguer, Valencia, Universitat de València.

Dumanoir, Virginie (1998) «Melodía y texto. El caso de los romances viejos», en Virginie Dumanoir (ed.) Música y literatura en la España de la Edad Media y del Renacimiento. Mesa redonda (15-16 de junio de 1998) Madrid, Casa de Velázquez, 2003, pp.107-117.

Fabris, Dinko (1993) «El nacimiento del mito musical de Nápoles en la época de Fernando el Católico», Nassarre, IX-2, pp. 53-93.

Fabris, Dinko (1996) «Giochi musicali e veglie «alla senese» nelle città non toscane dell'Italia rinascimentale», en Irene Alm-Alyson McLamore y Colleen Reardon (eds.) Musica Franca. Essays in bonour of Frank. A.D'Accone, Stuyvesant, NY, Pendragon Press, pp.213-229.

Fernández de Heredia, Joan (1913) Obras de Joan Fernandez de Heredia, poeta valenciano del siglo XVI, precedidas de una breve noticia biográfica y bibliográfica del autor Francisco Marti Grajales, Valencia, Manuel Belenguera y Molera.

SCRIPTA, Revista internacional de literatura i cultura medieval i moderna, núm. 5 / juny 2015 / pp. 229 - 252 
Fiorentino, Giuseppe (en prensa) «Discantar sobre Conde Claros». Técnicas de improvisación instrumental en la tradición española del Renacimiento de la oralidad a la escritura y de la escritura a la oralidad.

García Mercadal, José (1942) Extranjeros en Espana. La segunda mujer del rey católico, Dona Germana de Foix: última reina de Aragón, Balcelona, Juventud.

García Morales, José (1951) Libro de motes de dams y Caballeros, intitulado el juego de mandar, José García Morales (ed.), Barcelona, Torculum.

Garretas Díez, J. (1999) «Fiestas, torneos y juegos cortesanos en el Reinado de los Reyes Católicos. Divisas, motes y momos», Revista de Historia Jerónimo Zurita, 74, pp. 163-174.

Gásser, Luis (1996) Luis Milan on sixteenth-century performance practice, Bloomington-Indianapolis, Indiana University press.

Griffiths, John (2003) «Luis Milán, Alonso Mudarra y la canción acompanada», Edad de Oro, XXII, pp. 7-28.

Griffiths, John «Luis Milán», Semblanzas de compositores españoles, 14, (http:// recursos.march.es/web/ musica/publicaciones/semblanzas/pdf/milan.pdf)

Gómez Muntané, Maricarmen (2012) Historia de la música española e hispanoamericana. II: De los Reyes Católicos a Felipe II, ed. Maricarmen Gómez Muntané, Madrid, Fondo de Cultura Económica de España.

Haar, James (1962) «On musical games in the 16th century», Journal of the American Musicological Society, XV, pp. 22-34.

Haar, James (1981) «Arie per cantar stanze ariostesche. L'Ariosto: la musica, i musicisti», Maria Antonella Balsamo (ed.), Firenze, Leo S. Olschki, pp. 31-46.

Haar, James (1983) «The Courter as Musician. Castiglione's View of Science and Art of Music», en Robert Hanning y David Rosand (eds.) Castiglione: The Ideal and the Real in Renaissance Culture, New Haven, Yale University Press, pp.165-189.

Haar, James (1986) Essays on Italian Poetry and Music in the renaissance, 1350-1600, Berkeley-Los Angeles-London, University of North Carolina press.

Haar, James (1989) Monophony and the Unwritten Tradition, en Performance Practice (2 vols), eds. Howard Mayer Brown y Stanley Sadie, New York y London, W.W. Norton.

Haraszti, Emile (1955) «La technique des Improvisateurs de langue vulgaire et de latin au quattrocento, Revue belge de Musicologie, vol. 9, No. 1/2 , pp. 12-31.

Knighton, Tess (2001) Música y músicos en la corte de Fernando el Católico, 1474-1516, Zaragoza, Institución Fernando el Católico.

Lanza, Antonio (1973) Lirici toscani del Quattrocento, Roma, Bulzoni.

Lockwood, Lewis (1984) Music in Renaissance Ferrara (1400-1505), Cambridge (Massachausetts), Harvard University Press. 
López Alemany, Ignacio F. (2000) «Construcción de un cancionero y romancero efímero en la Corte del III Duque de Calabria», Estudos de Literatura Oral, 6, pp. 139-154.

López-Ríos, Santiago (2008) «La educación de Fernando de Aragón, Duque de Calabria, durante su infancia y juventud (1488-1502)", en Nicasio Salvador y C. Moya García (eds.) La literatura en la época de los Reyes Católicos, Madrid-Frankfurt, Iberoamericana-Vervuert, p. 127-144.

Lorenzetti, Stefano (2003) Musica e identità nobiliare nell'Italia del Rinascimento: educażione, mentalità, immaginario, Firenze, Leo S. Olschki.

Mcmurry, William M. (1977) «Ferdinand, Duke of Calabria, and the Estensi: A Relationship Honored», Music Sixteenth Century Journal, vol. 8, No. 3, pp. 17-30:23.

Menéndez Pidal, Ramón (1968) Romancero Hispánico, vol. 1, Madrid, Espasa-Calpe.

Menghini, Mario (1894) Le rime di Serafino de' Ciminelli dall'Aquila, Bologna, Romagnoli-Dall'Acqua.

Meregalli, Franco (1988) «La corte valenzana del Duca di Calabria ne El Cortesano di Luis Milán», AION Ser. Romanza, XXX, 1, p. 53-69.

Milà, Lluís del (2001) El cortesano, ed. Vicent Josep Escartí i Antonio Tordera, València, Biblioteca Valenciana-Ajuntament de València-Universitat de València, 2 vols.

Milà, Lluís del (2010) El cortesano, ed. Vicent Josep Escartí, Valencia, Biblioteca d'Autors Valencians.

Milán, Luis (1874) Libro intitulado El Cortesano, compuesto por D. Luis Milán [...], Madrid, Aribau y Cia.

Milán, Luis (1951) Libro de motes de dams y Caballeros, intitulado el juego de mandar, ed. José García Morales, Barcelona, Torculum.

Milán, Luis (1976) Libro de musica de Vibuela de mano intitulado El Maestro, en Der Originalnotation und einer Ubertragung herausgegeben, ed. von Leo Schrade, ripr. facs, Wiesbaden, Breitkopf \& Härtel.

Murino, Aegidius de (1864-67) Tractatus cantus mensurabilis, en Scriptorum de musica medii aevi, ed. Edmond de Coussemaker, Paris, Durand.

Nelson, Bernardette (2004) «The court of don Fernando de Aragón, Duke of Calabria in Valencia, c.1526-c.1550: Music, letters and the meeting of cultures», Early music, XXXII (2), pp. 194-222

Pèrcopo, Erasmo (1892) Il Chariteo: introduzione all'edizione critica delle Rime, Napoli, Accademia Reale delle Scienze.

Perugini, Carla (2012) «Biografía erótica de la corte valenciana (Luis de Milán y Juan Fernández de Heredia», Analecta Malacitana, XXXII (http://www.anmal.uma.es/numero32/Corte_valenciana. htm).

Pirrotta, Nino (1984) Music and culture in Italy from the Middle Ages to the Baroque, Cambridge (Massachausetts), Harvard University.

Pope, Isabel (1961) La vihuela y su música en el ambiente umanístico, NRFH, 15, pp. 364-376.

Ríos Lloret, Rosa (2003) Germana de Foix. Una mijer, una reina, una corte, Valencia, Biblioteca Valenciana.

SCRIPTA, Revista internacional de literatura i cultura medieval i moderna, núm. 5 / juny 2015 / pp. 229 - 252 
Rosa, Carlo Antonio de (1834) Ritratti poetici di alcuni nomini di lettere antichi e moderni del Regno di Napoli, Napoli, Fibreno, 1834, 2 vols.

Rodado Ruiz, Ana M. (2012) «Notas sobre la tradición animalística en el Juego trovado de Jerónimo de Pinar», en M. Haro, R. Beltrán, J. L. Canet \& H. Gassó (eds.) Estudios sobre el Cancionero General (Valencia, 1511), poesía, manuscrito e imprenta, Valencia, Universitat de València, pp. 371-384.

Rodríguez-Moñino, Antonio (1967) Cancionero de Romances en que están recompilados la mayor parte de los romances castellanos que esta agora se han compuesto, Madrid, Editorial Castalia.

Romeu i Figueras, José (1951) «Literatura valenciana en «El Cortesano» de Luis Milán», Revista valenciana de filologia, IV, (octubre-diciembre), Valencia, pp. 313-339.

Romeu i Figueras, José (2003) «La cort musical del Duc de Calábria», en Miscellánia homenatge a Rafael Martí de Viciana en el V centenari del seu naixement 1502-2002, Valencia 2003.

Ros-Fábregas, Emilio (2003) «Gadajoz el Músico» y Gari Sánchez de Badajoz: identificación de un poeta-músico andaluz del Renacimiento, en Virginie Dumanoir (ed.) Música y literatura en la España de la Edad Media y del Renacimiento. Mesa redonda (15-16 de junio de 1998) Madrid, Casa de Velázquez, pp. 55-75.

Solervicens Bo, Josep (1997) El diàleg renaixentista: Joan Lluís Vives, Cristófor Despuig, Lluís del Milá, Antoni Agustí, Barcelona, Publicacions de l'Abadia de Montserrat.

Torrefranca, Fausto (1939) Il segreto del Quattrocento. Musiche ariose e poesia popolaresca, Milano, Ulrico Hoepli.

Van der Werf, Hendrik (1972) The Chanson of the troubadours and trouveres. A study of the Melodies and their relation to the poems, Utrecht, Oosthoek.

Vega, María José «Poética y música en el Renacimiento. La invención del paradigma clásico», Academia edu (https://www.academia.edu/1976665/Po\%C3\%A9tica_y_m\%C3\%BAsica_en_ el_Renacimiento._La_invenci\%C3\%3n_del_paradigma_cl\%C3\%A1sico).

Vega Vázquez, Isabel (2006) El Libro de motes de dams y Caballeros de Luis Milán. Edición critica y estudio, Universidade de Santiago de Compostela.

Villanueva Serrano, Francesco (2011) «Poemas inéditos del vihuelista y escritor Luis Milán y nuevas consideraciones sobre su identidad: el ms. 2050 de La Biblioteca De Catalunya», Anuario Musical, 66, pp. 61-118.

Ward, John (1953) The «Vibuela de mano» and its Music, 1536-1576, Tesis, New York University. 